\title{
Nephrotic syndrome associated with breast cancer; when should it be treated?
}

\author{
Ezgi Coskun Yenigun ${ }^{1}$, Didem Turgut ${ }^{1}$, Erdem Alaguney ${ }^{2}$, Ramazan Ozturk ${ }^{1}$, \\ Serhan Iskinpasa ${ }^{1}$, Fatih Dede ${ }^{1}$
}

\begin{abstract}
Objectives: We hereby describe a 46-year woman with nephrotic syndrome and new-onset breast cancer.

Case: The patient was admitted to our hospital with peripheral edema and a mass in her right breast. Membranous glomerulonephritis (MGN) was the etiology of nephrotic syndrome. MGN has been reported in association with a wide variety of solid neoplastic diseases, although rarely occurs as a complication of breast carcinoma. We report a rare and a resistant case of MGN, who got breast cancer diagnosis concomitantly.

Conclusion: Patient had no improvement in proteinuria although breast cancer was under-controlled with chemotherapy and surgery
\end{abstract}

Key words: Breast cancer; glomerulonephritis; proteinuria; nephrotic syndrome

\section{Introduction}

Although nephrotic syndrome caused by membranous glomerulonephritis (MGN) has been reported in association with a wide variety of solid neoplastic diseases, it rarely occurs as a complication of breast carcinoma. We report a rare case of nephrotic syndrome caused by MGN, who got breast cancer diagnosis concomitantly and had persistent proteinuria after the treatment of malignancy. We review the literature on this unusual association.

\section{Case}

A 46-year woman was admitted to our department with symptoms of peripheral edema and a mass in right breast for a month. The patient had not been receiving any medications and systemic disease to cause the nephrotic syndrome. There was no history of fever, oral ulcers, joint pains, edema or rash. On physical examination, her blood pressure was $120 / 80$ $\mathrm{mmHg}$, pulse rate was $82 / \mathrm{min}$, and body temperature was $36.5^{\circ} \mathrm{C}$. She had pretibial edema and masses in right breast and right axillary while the examinations of other systems proved normal. Laboratory evaluation revealed serum urea $53 \mathrm{mg} / \mathrm{dl}$ (10-50), creatinine $0.87 \mathrm{mg} / \mathrm{dl}(0.6-1.3)$, total serum protein of $33 \mathrm{~g} / \mathrm{L}$ (64-83), serum albumin $13 \mathrm{~g} / 1$ (35-54), 24-hour protein excretion was 5.1 gr, erythrocytes sedimentation rate $81 \mathrm{~mm} / \mathrm{h}$, hemoglobin: $12.4 \mathrm{~g} / \mathrm{dl}$, white blood cell count of $9.2 \mathrm{~K} / \mathrm{ul}$, other hematologic and biochemical parameters were normal. Automatic full urine testing showed +4 proteinuria. Urine microscopy revealed epithelial cells.
HbsAg, HBeAg, anti-Hbs, anti-Hbe, anti$\mathrm{HCV}$ and HIV were all negative. CRP, C3, C4, IgG, IgA and $\operatorname{IgM}$ levels were normal. Antinuclear antibody, peripheral and cytoplasmic antineutrophil cytoplasmic antibody, antidouble-stranded DNA antibodies, anti-glomerular basal membrane antibody, rheumatoid factor and cryoglobulins were negative. Abdominal ultrasonography was normal. The patient underwent a renal biopsy for assessment of the histological features of the nephrotic syndrome and breast biopsy; and diagnosed membranous glomerulonephritis and invasive ductal carcinoma respectively. There was no evidence of distance metastasis. The patient was started on diuretic and neoadjuvant chemotherapy and performed a modified radical mastectomy two months later. Postoperatively she had taken adjuvant chemotherapy with cyclophosphamide $600 \mathrm{~g} / \mathrm{m} 2$, adriamycin $60 \mathrm{mg} / \mathrm{m} 2$, 5-fluorouracil $600 \mathrm{mg} / \mathrm{m} 2$ and radiotherapy. Breast cancer was accepted as under control by ten months after the diagnosis. In terms of MGN, she was followed up with RAS blockade and diuretic treatment. The patient had no evidence of recurrence of renal disease for 16 months after diagnosis. After 16 months, laboratory tests revealed proteinuria (4 $\mathrm{gr} / 24 \mathrm{~h}$ ) and hypoalbuminemia (22 g/l) so we started prednisone as $1 \mathrm{mg} / \mathrm{kg} /$ day dosage and cyclosporine as $4 \mathrm{mg} / \mathrm{kg} /$ day dosage. At the third month of the therapy, proteinuria remarkable decreased to $1 \mathrm{gr} / 24 \mathrm{~h}$, and the patient felt well 


\section{Discussion}

Nephrotic syndrome can be due to secondary causes. Depending on the age of the patient, cancer may be an important cause of nephrotic syndrome, as has been observed in as many as $22 \%$ of patients over 60 years presenting with MGN (1). A review of the literature shows that nephrotic syndrome is a rare complication of breast carcinoma (4\%), although mostly occur in the carcinomas of lungs (49\%) and gastrointestinal tract (23\%) (2). The relationship between nephrotic syndrome and malignancy is inconsistent. According to literature, $40-50 \%$ of patients have symptomatic nephrotic syndrome before the diagnosis of cancer. In $15-20 \%$ of patients cancer precedes the diagnosis of nephrotic syndrome and in the remaining patients there is simultaneous presentation of both diseases (3). The nephrotic syndrome often constitutes the prodromal stage of neoplastic disease.

Pathogenesis of paraneoplastic glomerulopathies remains controversial and mainly two mechanisms were suggested. First, tumors are important sources of antigens that may induce the production of specific antibodies and cause the formation of immune complexes in blood, which can subsequently deposit in renal tissue. Second, antigens with high affinity for basement membrane can settle directly in renal tissue and induce in situ formation of immune complexes with circulating antibodies (4). Both mechanisms would explain the role of chemotherapy or radical surgery in the resolution of the paraneoplastic nephrosis.

Removal or irradiation of the tumor is usually associated with dramatic decrease of the proteinuria whereas recurrence of the neoplasm is followed by increased proteinuria (5). Although the diagnosis of paraneoplastic glomerulopathy should theoretically be sustained by clinical and histological remission after radical surgical removal or chemotherapy-induced complete remission of the tumor, only few papers have reported this (3). Besides, some authors have suggested that nephrosis could be due to derangements in cell-mediated immunity in general and not necessarily to tumorassociated antigens that directly damage renal tissue. For this reason, it is possible that such a syndrome responds to prednisone, which is a "symptomatic" rather than "etiological" therapy (5).
In this case, while cancer was controlled with chemotherapy and surgery, there was no improvement in proteinuria. We did not find a definitive recommendation for the time required to wait after curative tumor treatment in the literature for glomerulonephritis. We waited spontaneous remission of the disease for about 18 months after treatment. Remission of glomerulopathy was failed so we planned to immunosuppressive therapy. In view of the patient's good response to immunosuppressive therapy, our case report seems to support the second hypothesis. We therefore suggest that, despite the paraneoplastic origin of MGN, in these patients it is useful to administer prednisone and other antiproteinuric agent in addition to adequate treatment for the tumor itself.

Conflict of Interest: The authors declare no potential conflicts of interest with respect to the research, authorship, and/or publication of this article.

\section{References}

1. Valcamonico F, Ferrari V, Simoncini E, Gregorini G, Vassalli L, Amoroso V., et al. Paraneoplastic Nephrotic Syndrome in Advanced Breast Cancer Patient. A Case Report. Tumori 2004; 90 (1): 154-156.

2. Eagen JW, Lewis EJ. Glomerulopathies of neoplasia. Kidney Int 1977; 11:297-306.

3. Pai P, Bone JM, McDicken I, Bell GM. Solid tumour and glomerulopathy. Q J Med 1996; 89:361-367.

4. Ozawa T, Pluss R, Lacher J, Boadecker E, Guggenheim S, Hammond W., et al. Endogenous immune complex nephropathy associated with malignancy: studies on the nature and immunopathogenic significance of glomerular bound antigen and antibody, isolation and characterisation of tumour specific antigen and antibody and circulating immune complexes. Q J Med 1975; 44:523-541.

5. Gagliano RG, Costanzi JJ, Beathard GA, Sarles HE, Bell JD. The Nephrotic Syndrome Associated with Neoplasia: An Unusual Paraneoplastic Syndrome Report of a Case and Review of the Literature. Am J Med 1976; 60:1026-1031.

Copyright (C) 2014 The Author(s); This is an open-access article distributed under the terms of the Creative Commons Attribution License (http://creativecommons.org/licenses/by/4.0), which permits unrestricted use, distribution, and reproduction in any medium, provided the original work is properly cited. All Rights reserved by international journal of Medical Science and Discovery and Lycians Press Inc. 